\title{
X-Shaped Slotted Patch Biomedical Implantable Antenna for Wireless Communication Networks
}

\author{
Sarosh Ahmad $\mathbb{D}^{1,2}$ Bilal Manzoor ${ }^{1}{ }^{3}{ }^{3}$ Salman Naseer $\left(\mathbb{D},{ }^{4}\right.$ Nilton Santos-Valdivia $\left(\mathbb{D},{ }^{2}\right.$ \\ Adnan Ghaffar $\left(\mathbb{D},{ }^{5}\right.$ and Muhammad Inam Abbasi $\mathbb{D}^{6}$ \\ ${ }^{1}$ Department of Electrical Engineering and Technology, Government College University Faisalabad (GCUF), 38000, Pakistan \\ ${ }^{2}$ Department of Signal Theory and Communications, Universidad Carlos III de Madrid (UC3M), 28911 Madrid, Spain \\ ${ }^{3}$ Department of Telecom Engineering, University of Engineering and Technology (UET), 47050 Taxila, Pakistan \\ ${ }^{4}$ Department of Information Technology, University of the Punjab Gujranwala Campus, 54000, Pakistan \\ ${ }^{5}$ Department of Electrical and Electronic Engineering, Auckland University of Technology, 1010 Auckland, New Zealand \\ ${ }^{6}$ Centre for Telecommunication Research \& Innovation (CETRI), Faculty of Electrical and Electronic Engineering \\ Technology (FTKEE), Universiti Teknikal Malaysia Melaka (UTeM), Melaka 76100, Malaysia
}

Correspondence should be addressed to Muhammad Inam Abbasi; muhammad_inamabbasi@yahoo.com

Received 11 November 2021; Revised 22 December 2021; Accepted 28 December 2021; Published 17 January 2022

Academic Editor: Pavlos I. Lazaridis

Copyright (C) 2022 Sarosh Ahmad et al. This is an open access article distributed under the Creative Commons Attribution License, which permits unrestricted use, distribution, and reproduction in any medium, provided the original work is properly cited.

\begin{abstract}
Biomedical implantable antennas have a major role in biomedical telemetry applications. Therefore, a compact-size low-profile implantable antenna working in industrial, scientific, and medical (ISM) band at $915 \mathrm{MHz}$ is presented. The presented antenna is a simple slotted patch fed with a coaxial probe of $50 \Omega$ impedance. The patch consists of four slotted resonators printed on a flexible Roger Duroid RT5880 substrate $\left(\varepsilon_{\mathrm{r}}=2.2, \tan \delta=0.0009\right)$ with the standard thickness of $0.254 \mathrm{~mm}$. The complete volume of the designed antenna is $7 \mathrm{~mm} \times 7 \mathrm{~mm} \times 0.254 \mathrm{~mm}\left(0.08 \lambda_{g} \times 0.08 \lambda_{g} \times 0.003 \lambda_{g}\right)$. The antenna covers the bandwidth from $800 \mathrm{MHz}$ to $1 \mathrm{GHz}(200 \mathrm{MHz})$ inside skin tissue. A good agreement between the simulation and measurements of the antenna has been obtained. Finally, the specific absorption rate (SAR) values have also been analyzed through simulations as $8.17 \mathrm{~W} / \mathrm{kg}$ inside skin over $1 \mathrm{~g}$ of mass tissue. The proposed SAR values are less than the limit of the Federal Communications Commission (FCC). This antenna is miniaturized and an ideal applicant for applications in biomedical implants.
\end{abstract}

\section{Introduction}

Implantable medical devices (IMDs) are playing a significant role in enhancing the living conditions of the patients day by day. The telemetry system has given us many advantages by using an implantable antenna for the wireless communications between IMDs and external monitoring devices, and those advantages can be in terms of high data rates and long-distance communications $[1,2]$. The schematic diagram of the implantable medical devices (IMDs) is presented in Figure 1. For the proposed model of the antenna, implantable medical devices (IMDs) are the key components [3]. The in-body antenna must be very thin in profile and should have very less values of SAR, and antennas should have flexibility for human care purposes [4]. Therefore, dur- ing the design stage, the antenna must be compatible and flexible along with the human body. Human body tissues can interfere with the operating frequency which can damage the tissues; that is why the antenna should have broader bandwidth that can cover the required frequency band after being tested on human tissues [5]. The radiation properties of the antenna change rapidly due to the multiple layer structure of the human body. The human structure has skin, fat, bone, muscle, and blood tissues. These tissues have different dielectric properties which make it difficult for designing a biocompatible antenna to be utilized for the human body applications [6]. Many in-body antennas are designed for wireless communication at midradio band ranges between 402 and $405 \mathrm{MHz}$ [7-11] and at ISM band ranges between 2.4 and $2.48 \mathrm{GHz}$ [12-17]. A compact- 


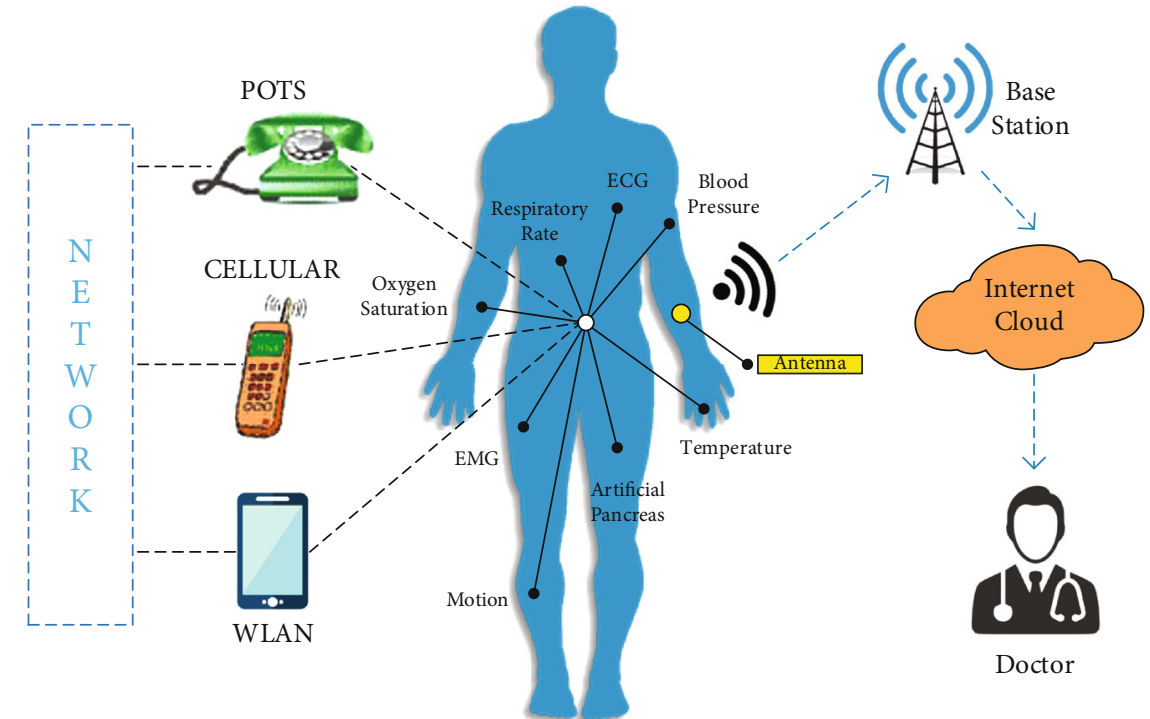

FIgURE 1: Schematic diagram of the implantable medical devices (IMDs).

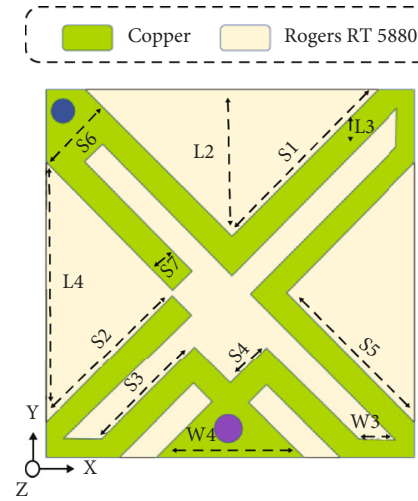

(a)

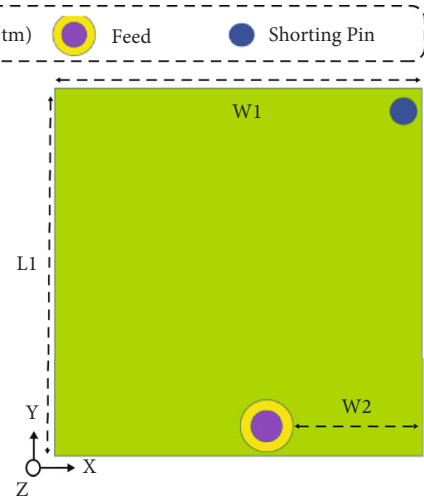

(b)

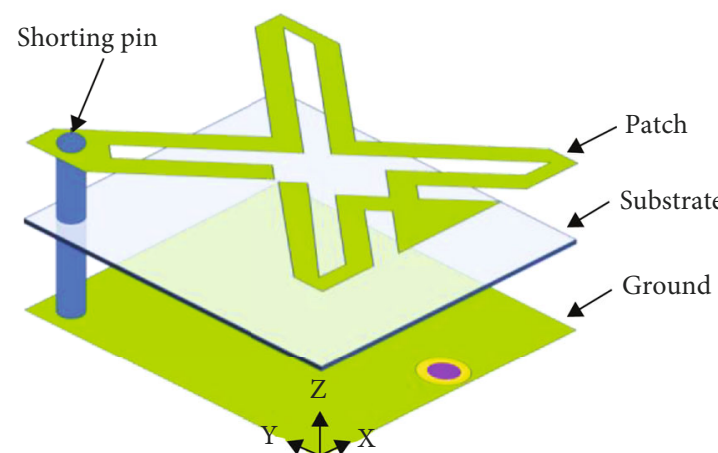

(c)

FIgURE 2: The proposed low-profile antenna with dimensions: (a) front view, (b) back view, and (c) exploded view.

sized broadband antenna for the implementations in biomedical implants operating at the MICS band $(403 \mathrm{MHz})$ was presented in [8]. A semiflexible Roger 6010 substrate material was used with the thickness of $1.27 \mathrm{~mm}$. SAR values were calculated as $284.5 \mathrm{~W} / \mathrm{kg}$ over $1 \mathrm{~g}$ that is very high than our proposed design. Another ISM band biomedical antenna for implantable applications based on the polyimide substrate was reported in [10].

The antenna had a realized gain of $-16.8 \mathrm{~dB}$ and the operational bandwidth of $1.22 \%$. The complete area of the antenna was $25 \times 20 \mathrm{~mm}^{2}$. The realized gain and the operating bandwidth were reported as $-34.9 \mathrm{~dB}$ and $14.9 \%$ over the reported frequency. A small-size in-body circularly polarized antenna with improved impedance matching for medical utilizations was presented in [18]. The radiating patch has circular shape, and there was an X-shaped slot inside the ground plane. The material used for the substrate was Rogers 3010 with a substrate height of $0.634 \mathrm{~mm}$. Because of the two-layered substrate, the antenna profile is thick. But the antenna was less biocompatible to the human body and has high specific absorption rate (SAR) value of about
$649 \mathrm{~W} / \mathrm{kg}$ which is greater than the standard limit of IEEE/ IEC 6270-1 standard over $1 \mathrm{~g}$ of mass tissue. Another implantable antenna at $915 \mathrm{MHz}$ for wireless power transfer is reported in [19]. The complete size of the antenna was $11 \times 11 \times 1.27 \mathrm{~mm}^{3}$, printed on a Roger 3010 substrate with an impedance bandwidth of $3.8 \%$ and the realized gain of about $-29 \mathrm{~dB}$. But the SAR values were not calculated, and the size of the antenna was still large with less bandwidth. An ISM band antenna for the devices in biomedical applications was reported in [20]. The antenna's size was $15 \times 15$ $\times 1.27 \mathrm{~mm}^{3}$, printed on a Roger 3010 substrate and operating at $915 \mathrm{MHz}$ with the operation bandwidth of $10.6 \%$. The antenna was being tested inside the skin, and its SAR values were found to be $517 \mathrm{~W} / \mathrm{kg}$ which is a very large value than our proposed design, while another wideband implantable antenna for medical applications at the frequency of $915 \mathrm{MHz}$ was proposed in [21]. The overall size of the antenna was $3.14 \times 22.09 \times 1.27 \mathrm{~mm}^{3}$, and the substrate material used was Roger 3010 with a thickness of $1.27 \mathrm{~mm}$. The impedance bandwidth was reported as $12.2 \%$, and the realized gain was $-32.8 \mathrm{~dB}$ at $915 \mathrm{MHz}$. The SAR values were 
TABLE 1: List of the parameters of the proposed antenna.

\begin{tabular}{lccc}
\hline Parameters & Values $(\mathrm{mm})$ & Parameters & Values $(\mathrm{mm})$ \\
\hline L1 & 7 & S1 & 3.94 \\
L2 & 2.79 & S2 & 3.34 \\
L3 & 0.7 & S3 & 1.9 \\
L4 & 4.8 & S4 & 0.7 \\
W1 & 7 & S5 & 3.4 \\
W2 & 3 & S6 & 1.4 \\
W3 & 0.7 & S7 & 0.5 \\
W4 & 2.7 & S8 & 3.5 \\
\hline
\end{tabular}

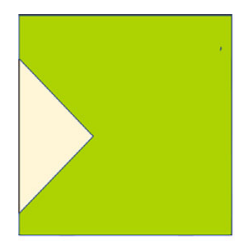

Step I

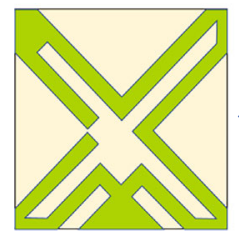

Step IV
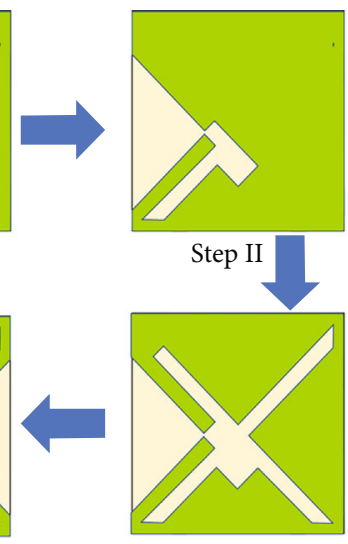

Step III
Figure 3: Implantable antenna design procedure: (a) truncated patch (step I), (b) slotted truncated patch (step II), (c) X-shaped slotted patch (step III), and (d) proposed design (step IV).

calculated as $778 \mathrm{~W} / \mathrm{kg}$. The antenna had large size and large SAR value as compared to our proposed design.

This article describes a compact-size implantable antenna for the biomedical applications operating in the ISM band at $915 \mathrm{MHz}$, sized at $7 \times 7 \times 0.254 \mathrm{~mm}^{3}$ $\left(0.08 \lambda_{g} \times 0.08 \lambda_{g} \times 0.003 \lambda_{g}\right)$. The design employs a Rogers RT5880 substrate $\left(\varepsilon_{\mathrm{r}}=2.2, \tan \delta=0.0009\right)$. At $915 \mathrm{MHz}$, the antenna's radiation has an omnidirectional radiation pattern both in the $E$ - and $H$-plane. The proposed design is configured with the full ground plane with four slotted resonators, so that it can provide wider bandwidth and reduced antenna back-radiation towards human skin tissue. For instance, the area of the skin is kept $20 \times 20 \mathrm{~mm}^{2}$. Because of the novel modified patch, the proposed antenna covers the more bandwidth at $915 \mathrm{MHz}$, and the peak gain of the antenna is comparable with the previous research. Fundamentally, the efficiency and designed antenna's performance under the influence of the physical body are improved, and SAR values are significantly reduced. The antenna has achieved very less SAR values and more good agreement results between simulations and measurements. This paper comprises five sections. Section 1 introduces the research work. It covers the background of the proposed research, the statement of the problem, the objectives, and the significance of the research. Section 2

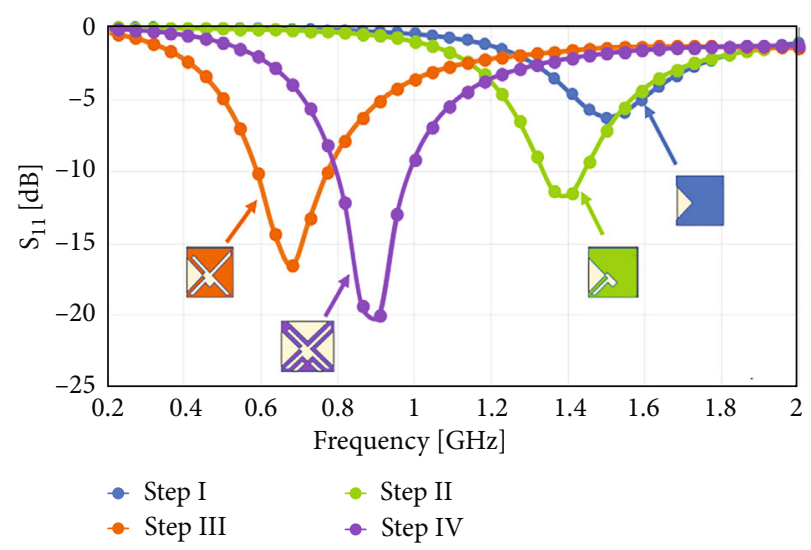

FIgURE 4: Simulation result comparison of the $S_{11}$ for the design steps shown in Figure 3.

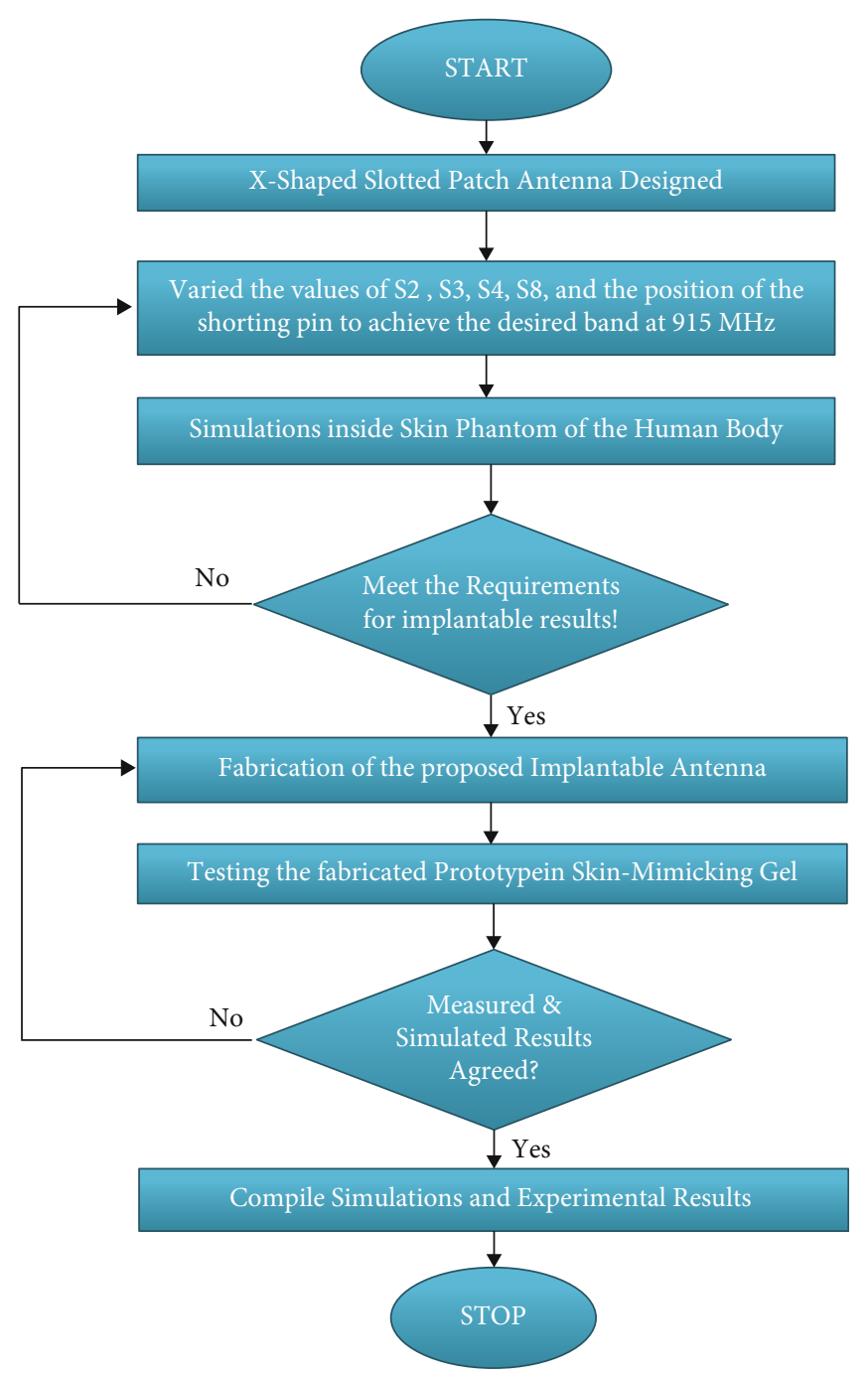

Figure 5: Design and optimization procedure of the proposed antenna. 

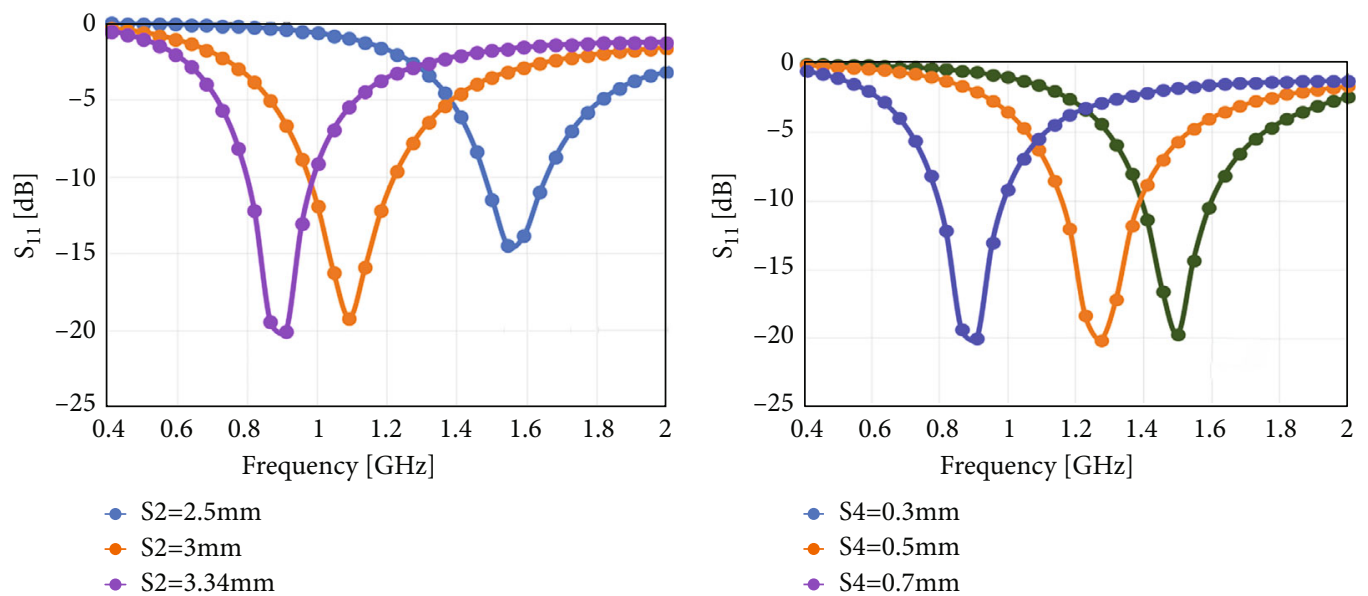

(a)

(b)

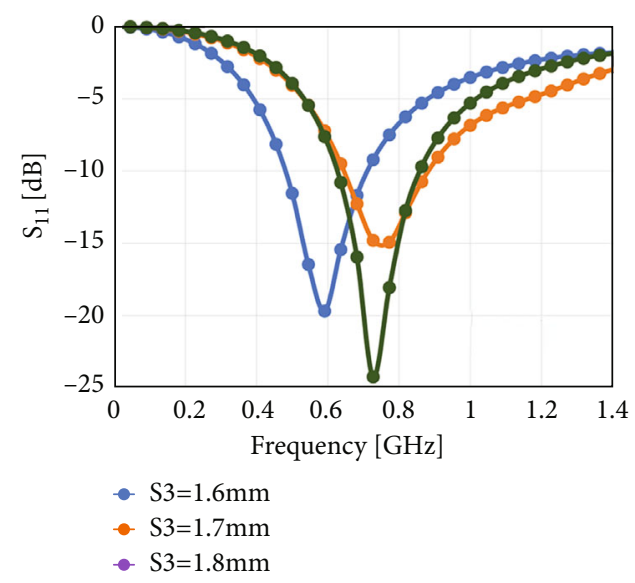

(c)

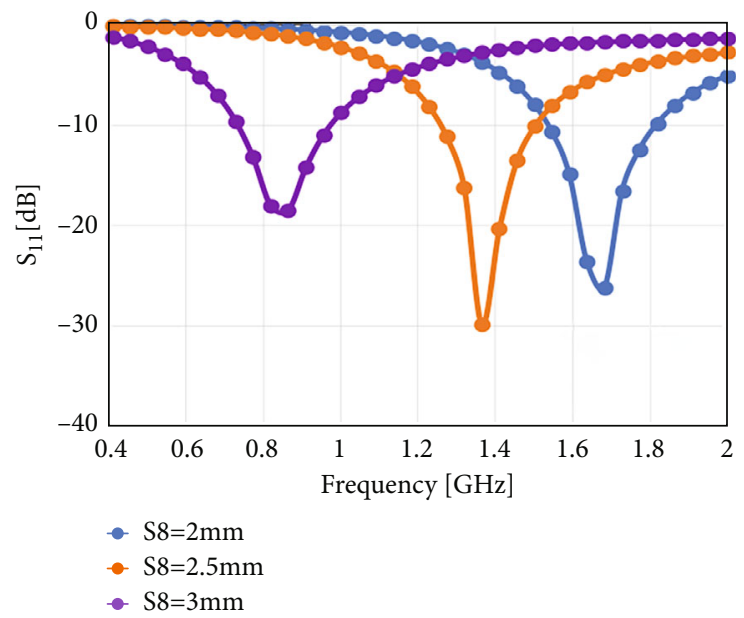

(d)

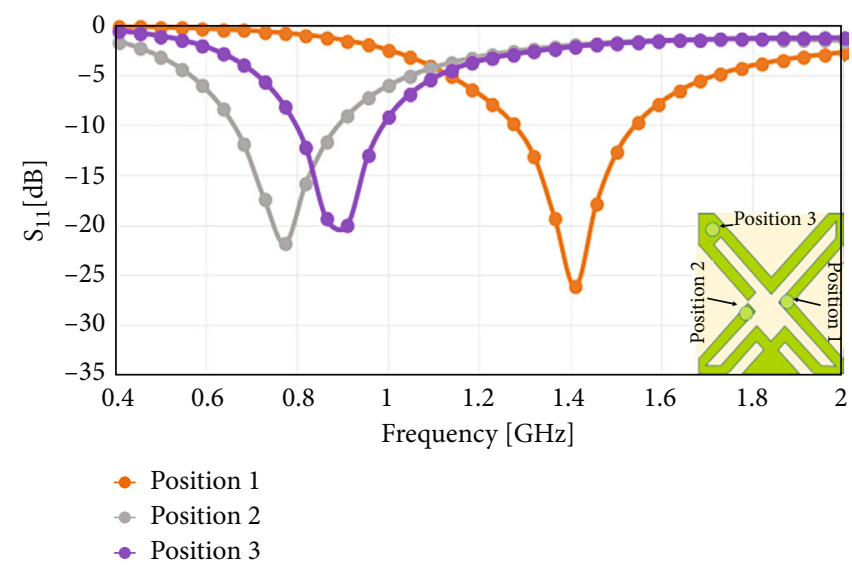

(e)

Figure 6: Parametric study of the antenna: (a) variation in " $S_{2}$ "; (b) variation in " $S_{4}$ "; (c) variation in " $S_{3}$ ”; (d) variation in " $S_{8}$ ”; (e) changing the position of the via.

covers the design analysis of the proposed antenna. Section 3 highlights the fabrication and measurement result and describes the antenna testing inside the skin, and Section 4 describes the conclusion.

\section{Proposed Antenna Design Analysis}

A slotted compact-size patch antenna with a novel-shaped radiator is fed with a coaxial probe. The presented antenna 


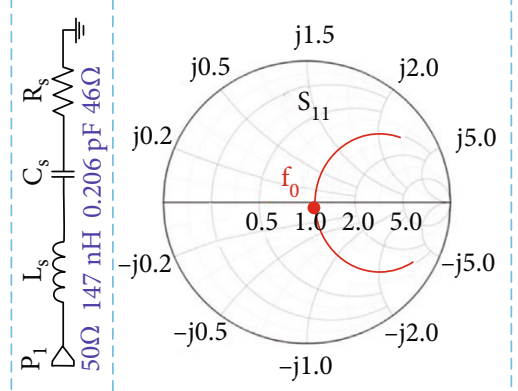

(a)

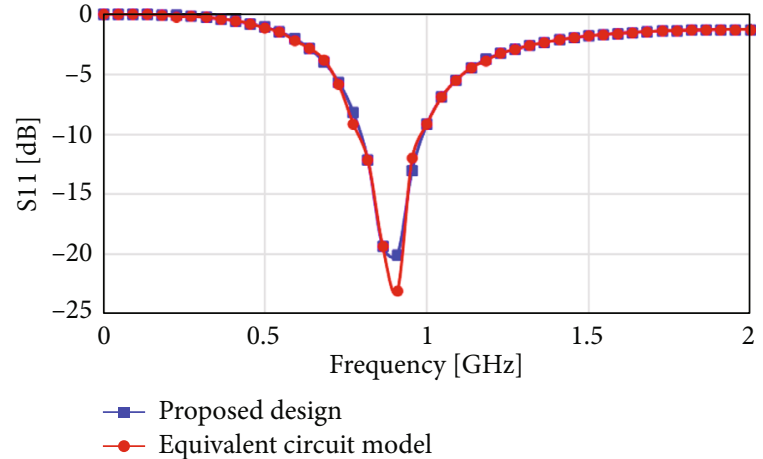

(b)

FIgure 7: (a) Circuit modeling and the impedance matching Smith chart. (b) Comparison of the $S_{11}$ of the proposed antenna and the equivalent circuit model.

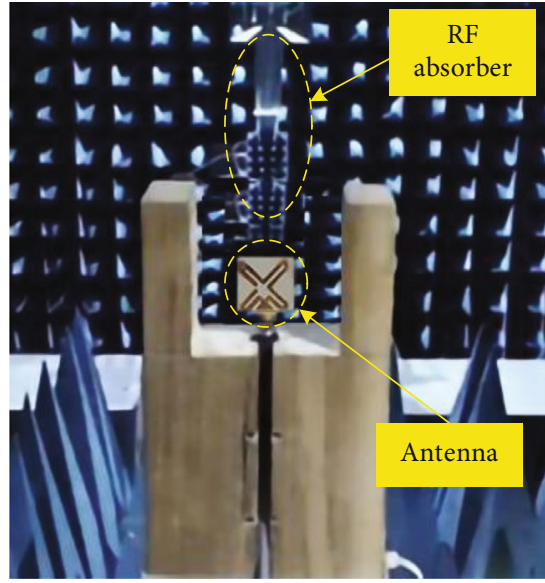

(a)

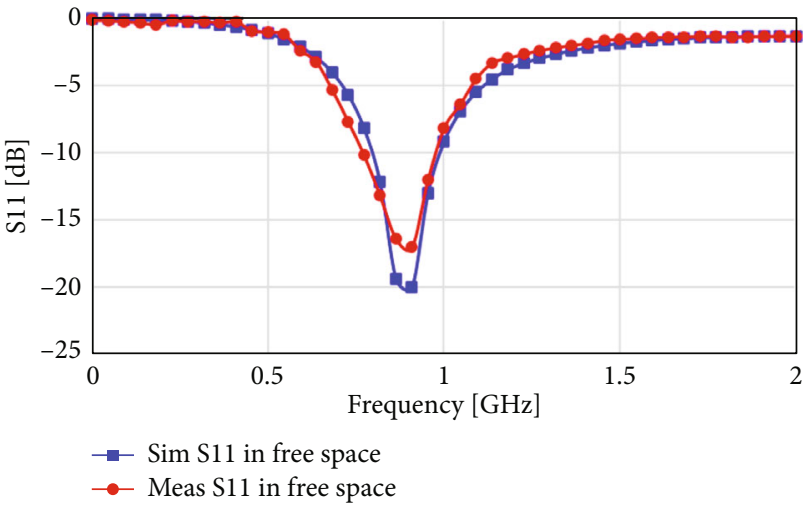

(b)

Figure 8: (a) Measurement setup inside chamber. (b) Comparison of the simulation and measurement reflection coefficients (dB) of the patch antenna in free space.

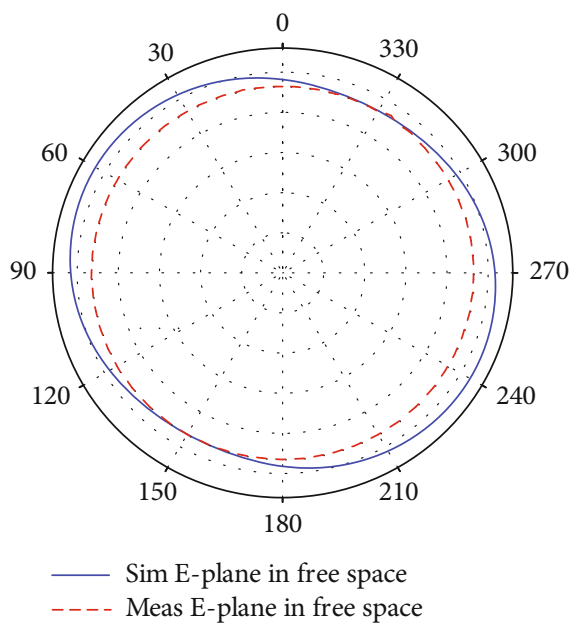

(a)

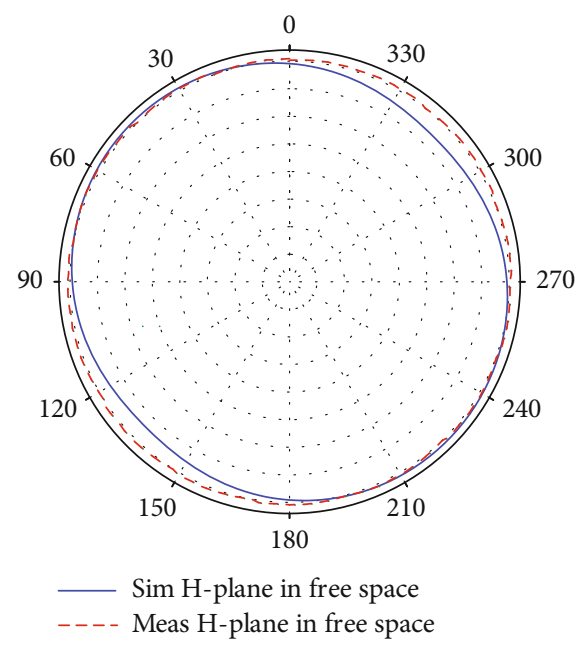

(b)

FiguRE 9: 2D radiation pattern of the antenna in free space at $915 \mathrm{MHz}$. 
contains distinct layers such as a full ground plane, a lowprofile $0.254 \mathrm{~mm}$ thick Roger RT5880 substrate $\left(\varepsilon_{\mathrm{r}}=2.2\right.$ and $\tan \delta=0.0009$ ), and a slotted patch, as shown in Figure 2. The complete volume of the antenna is $7 \times 7 \times$ $0.254 \mathrm{~mm}^{3} \quad\left(0.08 \lambda_{g} \times 0.08 \lambda_{g} \times 0.003 \lambda_{g}\right)$. The reported antenna is simulated in high-frequency structure simulator (HFSS) software, and the $S_{11}$ of the antenna is found to be $-25 \mathrm{~dB}$ at the working frequency of $915 \mathrm{MHz}$ and the operating bandwidth of the designed antenna seems to be $21.85 \%$. The optimized values of this antenna are summarized in Table 1.

2.1. Proposed Antenna Design Procedure. The design procedure of the proposed implantable antenna is explained as follows:

(1) In step I (Figure 3(a)), a triangular-shaped slot is introduced on the left side of the patch to generate a frequency band at $1.5 \mathrm{GHz}$, but return loss is not less than $-10 \mathrm{~dB}$ as can be seen in Figure 4

(2) Then, in step II (Figure 3(b)), in order to keep the value of the $S_{11}(\mathrm{~dB})$ less than $-10 \mathrm{~dB}$ and to shift the frequency band towards a lower band, a Tshaped slot is introduced in a truncated patch to operate the antenna at $1.4 \mathrm{GHz}$

(3) Then, in step III (Figure 3(b)), an X-shaped slot is introduced inside the patch. By introducing this slot, it has shifted the band from $1.4 \mathrm{GHz}$ to $0.7 \mathrm{GHz}$ $(700 \mathrm{MHz})$

(4) Then, in step IV (Figure 3(c)), the proposed novel shape is designed to help to resonate the antenna at the desired frequency at $0.915 \mathrm{GHz}$

(5) Figure 5 indicates the diagrammatic flow of the proposed antenna to show the entire work procedure

2.2. Parametric Analysis of the Proposed Antenna. The analysis of parameters of the implantable antenna is well explained in this section. The reflection coefficient at $0.915 \mathrm{GHz}$ can be adjusted by varying the values of the important parameters such as length of the patch resonator " $S_{2}$," width of the feed patch " $S_{4}$," length of the patch slot at $45^{\circ}$ angle " $S_{3}$," length of the upper left resonator of the patch " $S_{8}$," and changing the position of the via as presented in Figure 6. Figure 6(a) illustrates that by selecting the range of value of " $S_{2}$ " from $2.5 \mathrm{~mm}$ to $3.34 \mathrm{~mm}$, the frequency band shifted from $1.6 \mathrm{GHz}$ to $0.915 \mathrm{GHz}(685 \mathrm{MHz})$. When the value of the " $S_{4}$ " is changed from $0.3 \mathrm{~mm}$ to $0.7 \mathrm{~mm}$, then the frequency band shifted from $1.5 \mathrm{GHz}$ to $0.915 \mathrm{GHz}$ $(585 \mathrm{MHz})$ as presented in Figure 6(b). From Figure 6(c), it is also noticed that when the values of the " $S_{3}$ " are varied from $1.6 \mathrm{~mm}$ to $1.8 \mathrm{~mm}$, then the frequency band increases from $0.60 \mathrm{GHz}$ to $0.75 \mathrm{GHz}(150 \mathrm{MHz})$. Again, when the value of " $S_{8}$ " is varied from $2 \mathrm{~mm}$ to $3 \mathrm{~mm}$, then there is a shift in the frequency from $1.7 \mathrm{GHz}$ to $0.9 \mathrm{GHz}(800 \mathrm{MHz})$ as shown in Figure 6(d). By changing the position of the via in the proposed patch antenna, the frequency band shifted higher to our targeted frequency band. It is noticed

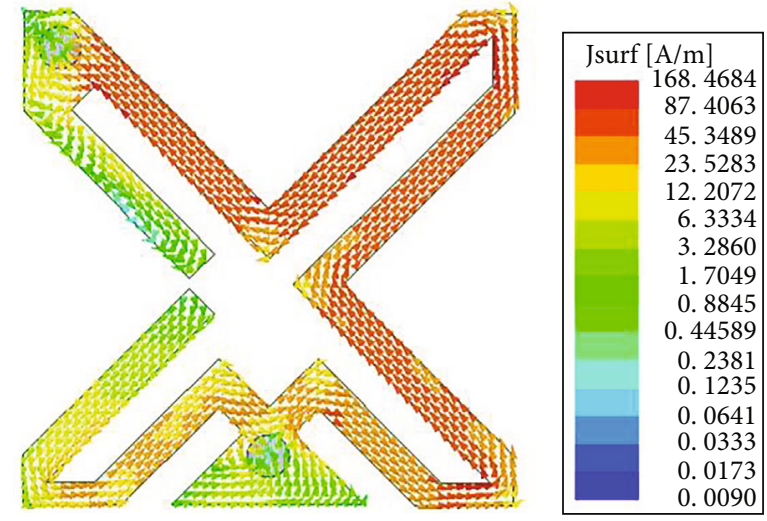

FIgURe 10: Current distribution throughout the patch at $915 \mathrm{MHz}$.

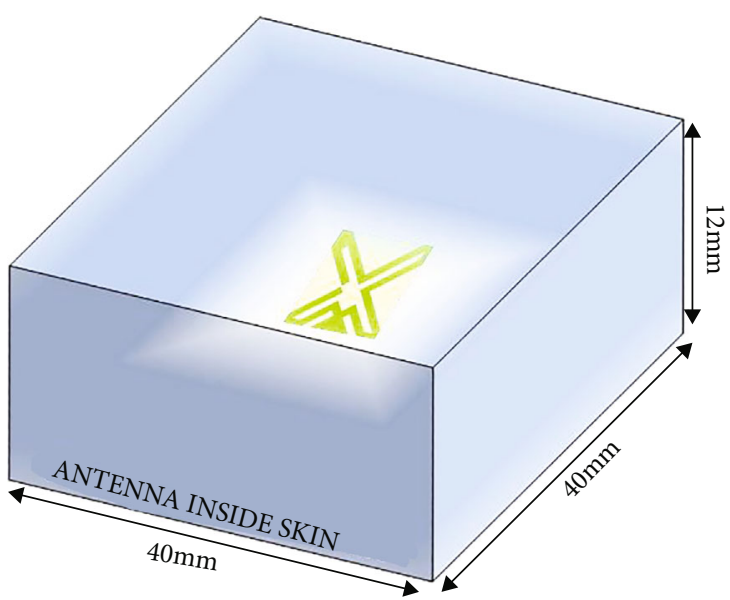

Figure 11: Perspective view of the skin phantom box.

from Figure 6(e) that when the via is placed at position 1, then the frequency band was $1.4 \mathrm{GHz}$, and we got the $0.8 \mathrm{GHz}$ band by changing the via from position 1 to position 2, and finally we achieved our desired frequency band $0.915 \mathrm{GHz}$ by changing the via from position 2 to position 3 .

2.3. Equivalent Circuit Modeling. An equivalent circuit model for the proposed implantable antenna is designed using Advanced Design System (ADS) software. Figure 7(a) indicates the circuit model and the impedance matching Smith chart for the proposed antenna system. The circuit model consists of one capacitor, a resistor, and an inductor. Figure $7(\mathrm{~b})$ presents the comparison between the reflection coefficient obtained from the proposed antenna and the proposed circuit model.

\section{Results and Discussion}

3.1. Antenna in Free Space. The designed biomedical implantable patch antenna is fabricated on a Roger RT5880 substrate with thickness of $0.254 \mathrm{~mm}$ and tested inside free space. A vector network analyzer (VNA) is used to measure the $S_{11}$ of the implantable antenna. In the case of the simulated results, the designed antenna covers the 


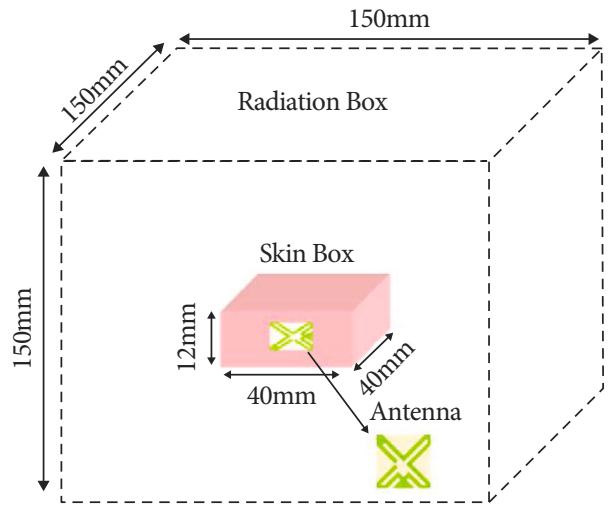

(a)

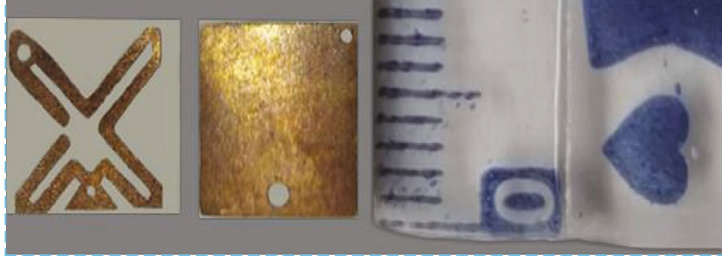

(b)

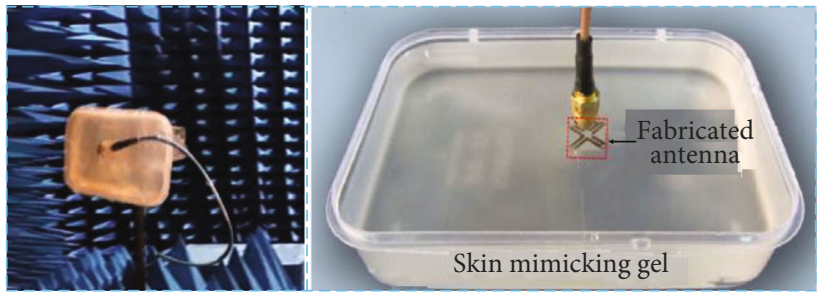

(c)

FIGURE 12: Antenna inside the skin of human tissues: (a) perspective view, (b) fabricated prototype of the antenna, and (c) experimental setup to measure the pattern and $S_{11}$.

bandwidths from $800 \mathrm{MHz}$ to $1000 \mathrm{MHz}(200 \mathrm{MHz})$ at $915 \mathrm{MHz}$ while in the case of the measurements, the antenna covers the bandwidth from $795 \mathrm{MHz}$ to $998 \mathrm{MHz}(203 \mathrm{MHz})$ at $915 \mathrm{MHz}$ as can be seen in Figure 8 .

The $E$ - and $H$-planes of the antenna are simulated and measured in free space (see Figure 9). The twodimensional (2D) radiation pattern describes the behavior of the antenna. The designed antenna behaves as an omnidirectional pattern in both planes at the $915 \mathrm{MHz}$ frequency band. The current density of the implantable antenna is shown in Figure 10. The current mainly flows around the upper- and bottom-sided resonators and feed patch. The red colored arrows indicate that the portion of the antenna has major contribution in operating at the desired frequency band.

3.2. Antenna inside the Skin. To explore the appropriateness of the antenna inside the skin for biomedical telemetry applications, the proposed design is simulated and tested inside skin tissue in this section. Consequently, to design an antenna for the applications in biotelemetry that had high precision, the presence of the human body phantoms must be taken into consideration while calculating SAR. For that, the antenna performance in proximity of human phantoms and the SAR values at $915 \mathrm{MHz}$ are also evaluated. The area of the phantom box is $20 \times 20 \mathrm{~mm}^{2}$ as can be seen in Figure 11. HFSS Studio is used for simulating the proposed antenna.

In an ideal case, in-body antennas should be planned to avoid the significant coupling effects from the human tissues. While testing the antenna inside the skin of the human body, it is placed $2 \mathrm{~mm}$ deep inside the skin tissue

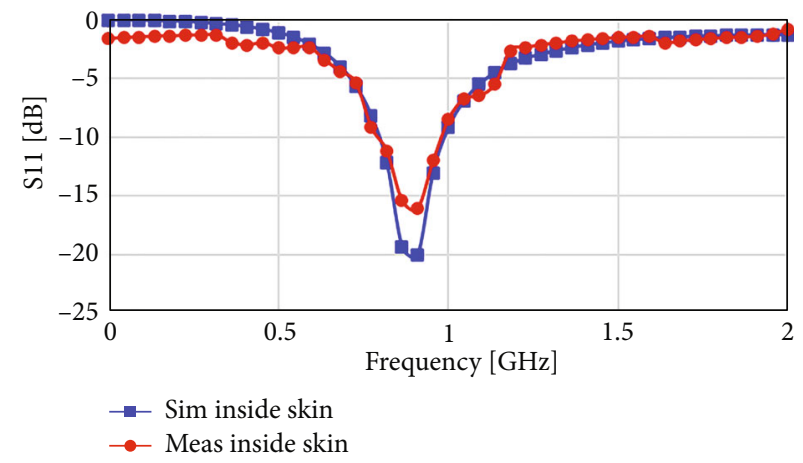

Figure 13: Comparison between the simulated and measured $S_{11}$ of the antenna inside skin tissue.

as shown in Figure 12. To estimate these effects, the reported design is kept inside a $40 \mathrm{~mm} \times 40 \mathrm{~mm}$ box of skin tissue. A "skin-mimicking gel" with relative permittivity $\left(\varepsilon_{\mathrm{r}}\right)$ of 43 and electrical conductivity $(\sigma)$ of 1.40 is used, as its properties are very close to those of human skin tissue.

The contrast between the simulated and measured $S_{11}$ of the antenna inside the skin is described in Figure 13. The simulated $S_{11}$ inside the skin indicates that the biomedical antenna operates from $780 \mathrm{MHz}$ to $1000 \mathrm{MHz}$ $(220 \mathrm{MHz})$ at $915 \mathrm{MHz}$ while the fabricated antenna inside the mimicking gel, on the other side, featured bandwidths from $785 \mathrm{MHz}$ to $998 \mathrm{MHz}(213 \mathrm{MHz})$. This proves that both simulated and measured results have good agreement among each other.

Figure 14 presents the $E$ - and $H$-planes of the simulation and measurement results of the radiation pattern inside skin tissue. The $2 \mathrm{D}$ radiation pattern describes the behavior of 


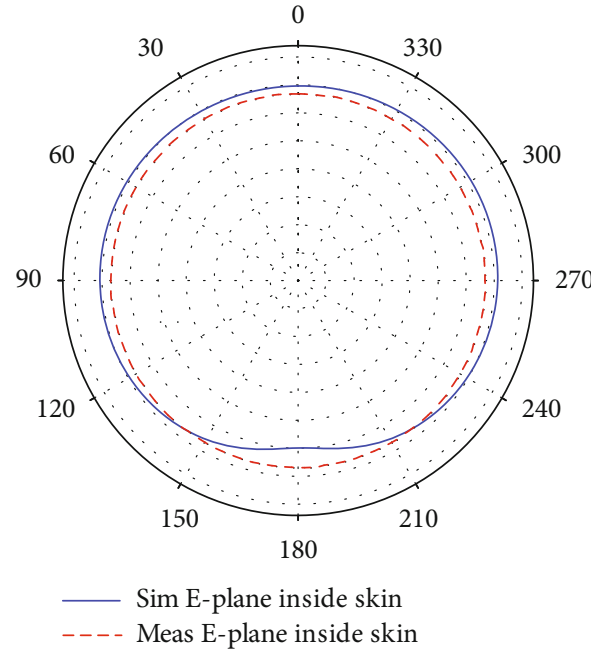

(a)

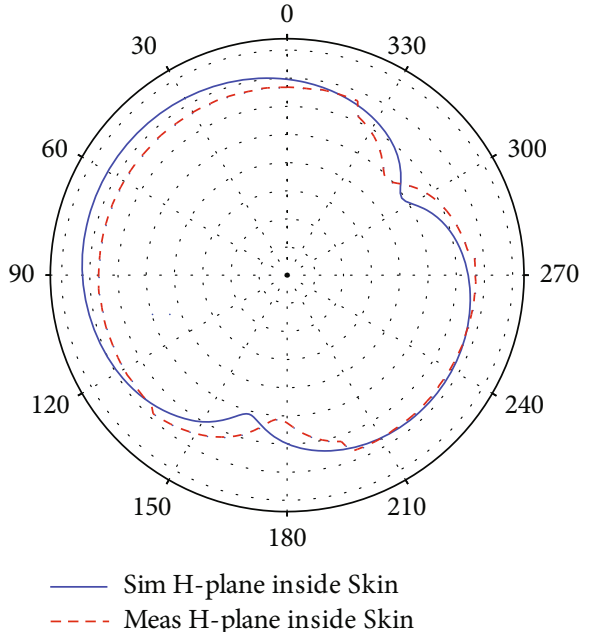

(b)

FIGURE 14: Simulated and measured far field results at $915 \mathrm{MHz}$ inside skin tissue.

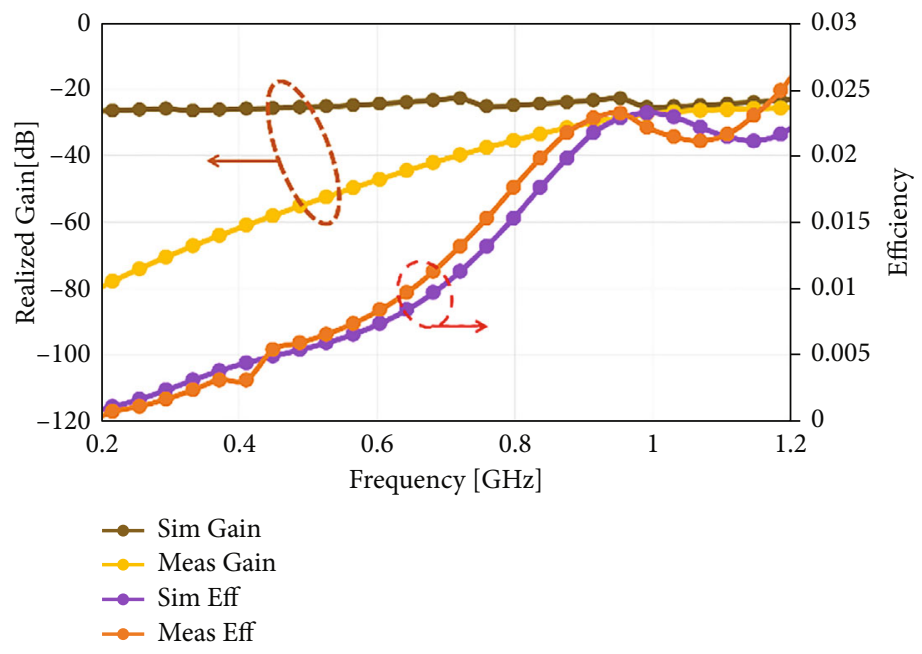

Figure 15: Simulated and measured gain and efficiency graph inside the skin.

the antenna inside the skin. These far field results prove that the antenna inside the skin has an omnidirectional radiation pattern in both planes at the $915 \mathrm{MHz}$ frequency band. The simulated realized gain value inside the skin is found to be $-22 \mathrm{~dB}$ at $915 \mathrm{MHz}$, whereas measurement results give the realized gain of $-28 \mathrm{~dB}$ at $915 \mathrm{MHz}$. The simulated and measured efficiency and gain graph is presented in Figure 15. The presented graph indicates that the antenna has simulated efficiency of $2.2 \%$ while the measured efficiency is $2.1 \%$ inside the skin.

3.3. Specific Absorption Rate (SAR). The radiations of electromagnetic waves may cause health risks to the human body, and such risks are calculated in terms of SAR. The relationship between the input power and the SAR is as follows [10]:

$$
\operatorname{SAR}=\frac{\sigma\left|E^{2}\right|}{\rho}
$$

where $\sigma$ and $\rho$ denote the thermal conductivity $(\mathrm{S} / \mathrm{m})$ and the mass density $\left(\mathrm{kg} / \mathrm{m}^{3}\right)$, respectively, while $E$ is the electric field intensity $(\mathrm{V} / \mathrm{m})$. The electric power intensity is related to the signal power as follows [13]:

$$
\text { Power }\left(\frac{\mathrm{W}}{\mathrm{m} 2}\right)=\frac{(E(\mathrm{~V} / \mathrm{m}))^{2}}{377} \text {. }
$$

SAR simulations were accomplished when the proposed antenna is kept inside the skin as well as inside the muscle. Input power pin is kept constant at $0.5 \mathrm{~W}$ with the SAR evaluated based on the IEEE/IEC 6270-1 standard, averaged over $1 \mathrm{~g}$ of mass tissue. SAR values inside the skin are calculated as $8.17 \mathrm{~W} / \mathrm{kg}$ at $915 \mathrm{MHz}$ as presented in Figure 16 .

3.4. Link Budget Analysis. The telemetry range between the implanted device and the external base station must be determined in order to successfully communicate biological data. However, the link budget estimates are affected by a 


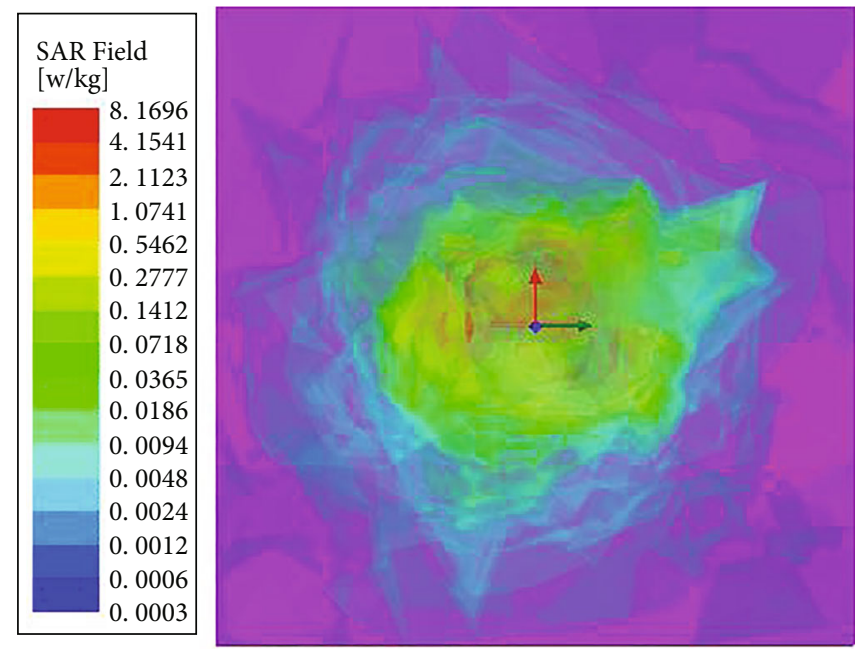

FIGURE 16: SAR distribution of the proposed antenna inside skin tissue over $1 \mathrm{~g}$ at $915 \mathrm{MHz}$.

variety of losses, including free space losses, cable losses, and antenna material and mismatch losses [14]. The link margins were calculated using the Friis equation to calculate the difference between the antenna power $\left(A_{\mathrm{P}}\right)$ and the necessary antenna power $\left(R_{\mathrm{P}}\right)$, and the link margin should be more than $20 \mathrm{~dB}$ for consistent communication. Table 2 lists the important parameters utilized in these computations. The following formula can be used to calculate $R_{\mathrm{p}}$ :

$$
R_{\mathrm{P}}=\frac{E_{\mathrm{b}}}{N_{\mathrm{o}}}+K T+B_{\mathrm{r}}
$$

The phase shift keying, Boltzmann's constant, temperature, and bit rate are represented by $E_{\mathrm{b}} / N_{\mathrm{o}}, K, T_{\mathrm{o}}$, and $B_{\mathrm{r}}$, respectively. $A_{\mathrm{P}}$, on the other hand, may be computed as follows:

$$
A_{\mathrm{P}}(d B)=P_{\mathrm{a}}+G_{\mathrm{a}}+G_{\mathrm{b}}+L_{\mathrm{f}} .
$$

The transmission power, implanted antenna gain, and receiver monopole antenna gain are represented by $P_{\mathrm{a}}$, $G_{\mathrm{a}}$, and $G_{\mathrm{b}}$, respectively. The free space losses are represented by $L_{\mathrm{f}}$, which may be calculated using the formula below:

$$
L(\mathrm{~dB})=20 \log \left(\frac{4 \pi d}{\lambda}\right)
$$

The distance between the implanted antenna and the external controlling device, which can range from 2 to 30 meters, is denoted by $d$. For the safety of patients, the European Research Council limits the input power to $25 \mathrm{~W}$ and the EIRP max $_{\text {mo }}$ for the ISM $(915 \mathrm{MHz})$ band to $20 \mathrm{dBm}$ [15]. For the ISM $(915 \mathrm{MHz})$ band, the in-body communication range was calculated. The availability of battery power and circuitry are the key problems of the IMDs. The skin implantation is considered depending on the application of the proposed antenna based on the input power. The anticipated transmission power $P_{\mathrm{t}}$ of the proposed antenna is $16 \mathrm{dBm}$,
TABle 2: Parameters of the link budget of the stated design.

\begin{tabular}{lcc}
\hline Parameters & Variables & Value \\
\hline Resonance frequency & $f_{\mathrm{o}}(\mathrm{MHz})$ & 915 \\
Noise power density & $N_{\mathrm{o}}(\mathrm{dB} / \mathrm{Hz})$ & -203.93 \\
Transmitter power & $P_{T x}(\mathrm{dBm})$ & -4 \\
Polarization mismatch loss & $P_{\mathrm{L}}(\mathrm{dB})$ & 1 \\
Temperature & $T_{\mathrm{o}}(\mathrm{Kelvin})$ & 273 \\
Free space path loss & $L_{\mathrm{f}}(\mathrm{dB})$ & Distance dependent \\
Transmitter antenna gain & $G_{T x}(\mathrm{dBi})$ & Scenario dependent \\
Receiver antenna gain & $G_{R x}(\mathrm{dBi})$ & 2 \\
Boltzmann constant & $K$ & $1.38 \times 10^{-23}$ \\
Available power & $A_{\mathrm{P}}(\mathrm{db})$ & Distance dependent \\
Bit rate & $B_{\mathrm{r}}(\mathrm{Mbps})$ & 1 \\
Required power & $R_{\mathrm{P}}(\mathrm{dB})$ & -134.64 \\
\hline
\end{tabular}

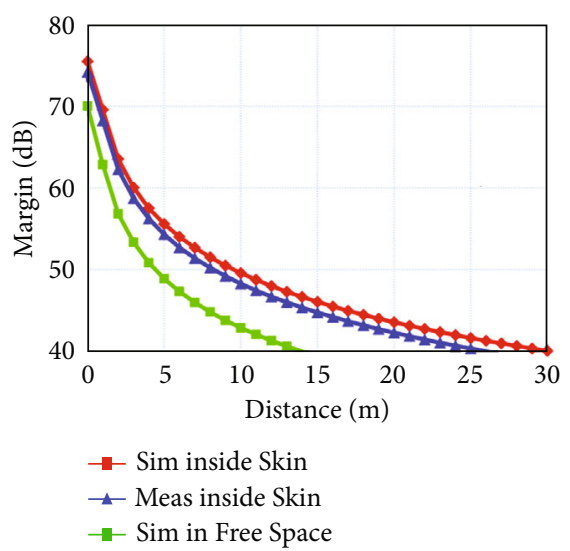

FIGURE 17: SAR distribution of the proposed antenna inside skin tissue over $1 \mathrm{~g}$ at $915 \mathrm{MHz}$. 
TABLE 3: Performance comparison of the proposed antenna with recent work.

\begin{tabular}{|c|c|c|c|c|c|}
\hline Ref. no. & Dimensions $\left(\mathrm{mm}^{3}\right) /\left(\lambda_{g}{ }^{3}\right)$ & $\begin{array}{l}\text { Operating frequency } \\
(\mathrm{GHz})\end{array}$ & $\begin{array}{l}\text { Realized gain } \\
(\mathrm{dB})\end{array}$ & $\begin{array}{l}\text { Operating bandwidth } \\
\text { (\%) }\end{array}$ & $\begin{array}{c}\text { SAR (W/kg)@ } \\
1 \mathrm{~g}\end{array}$ \\
\hline [8] & $(23 \times 16.4 \times 1.27) /(0.098 \times 0.070 \times 0.005)$ & 0.402 & -34.9 & 12.9 & 284.5 \\
\hline [10] & $(25 \times 20 \times 0.07) /(0.34 \times 0.27 \times 0.00095)$ & 2.45 & -16.8 & 1.22 & 1.0 \\
\hline [11] & $(15 \times 21.5 \times 1.5748) /(0.39 \times 0.56 \times 0.039)$ & 2.45 & $<-15$ & 3.2 & Not calculated \\
\hline$[12]$ & $(3.14 \times 100 \times 2.54) /(0.082 \times 2.6 \times 0.066)$ & $0.4 / 2.45$ & $-33.1 /-14.55$ & $38.1 / 17.6$ & $241.5 / 149.7$ \\
\hline [14] & $(14 \times 14 \times 0.5) /(0.365 \times 0.365 \times 0.013)$ & 2.45 & -15.96 & 18.36 & 0.494 \\
\hline [16] & $(3.14 \times 28.6 \times 1.34) /(0.082 \times 0.748 \times 0.035)$ & $0.402 / 2.45$ & $-41 /-21.3$ & $41 / 27.8$ & $666 / 676$ \\
\hline$[17]$ & $(3.14 \times 23 \times 0.634) /(0.082 \times 0.60 \times 0.016)$ & 2.45 & -20.3 & 18.3 & 649 \\
\hline [18] & $11 \times 11 \times 1.27 /(0.107 \times 0.107 \times 0.0123)$ & 0.915 & -29 & 3.8 & Not calculated \\
\hline [19] & $15 \times 15 \times 1.27 /(0.14 \times 0.14 \times 0.0123)$ & 0.915 & -27 & 10.6 & 517 \\
\hline$[20]$ & $3.14 \times 22.09 \times 1.27 /(0.030 \times 0.22 \times 0.0123)$ & 0.915 & -32.8 & 12.2 & 778 \\
\hline $\begin{array}{l}\text { This } \\
\text { work }\end{array}$ & $7 \times 7 \times 0.254 /(0.08 \times 0.08 \times 0.003)$ & 0.915 & -28 & 21.85 & 8.1 \\
\hline
\end{tabular}

and the bit rate $B_{\mathrm{r}}$ is $1 \mathrm{Mbps}$, based on the skin implanted devices. Figure 17 shows the simulated and measured link margin analysis inside skin tissue of the human body. Data at $1 \mathrm{Mbps}$ might be sent across a distance of more than $15 \mathrm{~m}$. It has been discovered that by altering the data rate and gain, the range of data transmission may be altered. Table 3 shows the performance comparison of the proposed work with some of the previously published relevant works.

\section{Conclusion}

This paper provides a low-profile ISM band compact-size patch antenna for the applications in biomedical implants. The presented antenna is simulated by using HFSS software. This proposed antenna resonates in the ISM band at $915 \mathrm{MHz}$. The antenna is designed on a Rogers material of RT/Duroid $5880\left(\varepsilon_{\mathrm{r}}=2.2, \tan \delta=0.0009\right)$ with complete dimensions of $7 \mathrm{~mm} \times 7 \mathrm{~mm} \times 0.254 \mathrm{~mm}$. The measured gain of the antenna inside the skin-mimicking gel is calculated as $-28 \mathrm{~dB}$ at $915 \mathrm{MHz}$, while the measured bandwidth of the antenna reported is $21.85 \%$ inside the skinmimicking gel. The SAR values are found to be $8.1 \mathrm{~W} / \mathrm{kg}$ inside the skin. Problems of compliance with biocompatibility and safety related to the construction of medical applications were also discussed. This antenna is miniaturized and an ideal applicant for in-body biomedical applications.

\section{Data Availability}

Data is available on request. The corresponding author can be contacted for any relevant data.

\section{Conflicts of Interest}

The authors declare that they have no conflicts of interest.

\section{Acknowledgments}

Research funding for this work is collaboratively provided by the Government College University Faisalabad (GCUF), Pakistan; Universidad Carlos III de Madrid (UC3M), Madrid, Spain; and Universiti Teknikal Malaysia Melaka (UTeM), Melaka, Malaysia.

\section{References}

[1] M. Yousaf, I. B. Mabrouk, M. Zada et al., "An ultraminiaturized antenna with ultra-wide bandwidth characteristics for medical implant systems," IEEE Access, vol. 9, pp. 40086-40097, 2021.

[2] A. Ghaffar, W. A. Awan, N. Hussain, S. Ahmad, and X. J. Li, “A compact dual-band flexible antenna for applications at 900 and $2450 \mathrm{MHz}$," Progress in Electromagnetics Research Letters, vol. 99, pp. 83-91, 2021.

[3] D. Nguyen and C. Seo, "An ultra-miniaturized antenna using loading circuit method for medical implant applications," IEEE Access, vol. 9, pp. 111890-111898, 2021.

[4] M. Yousaf, I. B. Mabrouk, F. Faisal et al., "Compacted conformal implantable antenna with multitasking capabilities for ingestible capsule endoscope," IEEE Access, vol. 8, pp. 157617-157627, 2020.

[5] M. S. Singh, J. Ghosh, S. Ghosh, and A. Sarkhel, "Miniaturized dual-antenna system for implantable biotelemetry application," IEEE Antennas and Wireless Propagation Letters, vol. 20, no. 8, pp. 1394-1398, 2021.

[6] Z. Xia, H. Li, Z. Lee et al., "A wideband circularly polarized implantable patch antenna for ISM band biomedical applications," IEEE Transactions on Antennas and Propagation, vol. 68, no. 3, pp. 2399-2404, 2020.

[7] L. Xu, Y. Bo, W. Lu, L. Zhu, and C. Guo, "Circularly polarized annular ring antenna with wide axial-ratio bandwidth for biomedical applications," IEEE Access, vol. 7, pp. 59999-60009, 2019.

[8] R. Li, B. Li, G. Du, X. Sun, and H. Sun, "A compact broadband antenna with dual-resonance for implantable devices," Micromachines, vol. 10, no. 1, p. 59, 2019. 
[9] K. N. Ketavath, D. Gopi, and S. S. Rani, "In-vitro test of miniaturized CPW-fed implantable conformal patch antenna at ISM band for biomedical applications," IEEE Access, vol. 7, pp. 43547-43554, 2019.

[10] K. K. Naik, S. C. Teja, B. V. Sailaja, and P. A. Sri, "Design of flexible parasitic element patch antenna for biomedical application," Progress in Electromagnetics Research M, vol. 94, pp. 143-153, 2020.

[11] N. H. Sulaiman, N. A. Samsuri, M. K. A. Rahim, F. C. Seman, and M. Inam, "Compact meander line telemetry antenna for implantable pacemaker applications," Indonesian Journal of Electrical Engineering and Computer Science, vol. 10, no. 3, p. $883,2018$.

[12] P. Loktongbam, D. Pal, and C. Koley, "Design of an implantable antenna for biotelemetry applications," Microsystem Technology, vol. 26, pp. 2217-2226, 2020.

[13] N. Ganeshwaran, J. K. Jeyaprakash, M. G. N. Alsath, and V. Sathyanarayanan, "Design of a dual-band circular implantable antenna for biomedical applications," IEEE Antennas and Wireless Propagation Letters, vol. 19, no. 1, pp. 119-123, 2020.

[14] W. Lei, H. Chu, and Y. Guo, "Design of a circularly polarized ground radiation antenna for biomedical applications," IEEE Transactions on Antennas and Propagation, vol. 64, no. 6, pp. 2535-2540, 2016.

[15] V. K. Gupta and D. Thakur, "Design and performance analysis of aCPW-fed circularly polarized implantable antenna for 2.45 GHz ISM band," Microwave and Optical Technology Letters, vol. 62 , no. 12, pp. 3952-3959, 2020.

[16] S. Shekhawat, S. V. Gunaram, and D. Bhatnagar, "CPW fed implantable elliptical patch antenna for biomedical application," AIP Conference Proceedings, vol. 2220, article 130068, 2020.

[17] L. Luo, B. Hu, J. Wu, T. Yan, and L.-J. Xu, "Compact dualband antenna with slotted ground for implantable applications," Microwave and Optical Technology Letters, vol. 61, no. 5, pp. 1314-1319, 2019.

[18] L. Xu, J. Xu, Z. Chu, S. Liu, and X. Zhu, "Circularly polarized implantable antenna with improved impedance matching," IEEE Antennas and Wireless Propagation Letters, vol. 19, no. 5, pp. 876-880, 2020.

[19] C. Liu, Y. Zhang, and X. Liu, "Circularly polarized implantable antenna for $915 \mathrm{MHz}$ ISM-band far-field wireless power transmission," IEEE Antennas and Wireless Propagation Letters, vol. 17, no. 3, pp. 373-376, 2018.

[20] K. Zhang, C. Liu, X. Liu, H. Guo, and X. Yang, "Miniaturized circularly polarized implantable antenna for ISM-band biomedical devices," International Journal of Antennas and Propagation, vol. 2017, 9 pages, 2017.

[21] Y. Zhang, C. Liu, X. Liu, K. Zhang, and X. Yang, “A wideband circularly polarized implantable antenna for $915 \mathrm{MHz}$ ISMband biotelemetry devices," IEEE Antennas and Wireless Propagation Letters, vol. 17, no. 8, pp. 1473-1477, 2018. 